\title{
The Interdependence of Organic and Biogenic Pollutants Concentrations in the Aspect of their Susceptibility to Biodegradation - A Case Study
}

\author{
Piotr Michał Bugajski ${ }^{*}$, Jan Pawełek' ${ }^{1}$ Karolina Jóźwiakowska ${ }^{1}$ \\ 1 University of Agriculture in Krakow, Mickiewicza Ave 24/28, 30-059, Krakow, Poland \\ * Corresponding author's email: p.bugajski@urk.edu.pl
}

\begin{abstract}
The aim of the research was to determine, the interdependence between COD and such parameters as: BOD 5 , TN and TP in raw wastewater and in mechanically treated wastewater using statistical methods, which would allow estimating the values of these parameters based on COD. Moreover, the aim of the study was to determine the susceptibility of wastewater before and after mechanical treatment to decomposition of organic and biogenic pollutants. The research was conducted from 2006 to 2015 in a collective wastewater treatment plant in Nowy Sącz. During the research period, 120 samples of raw and mechanically treated wastewater were collected and analyzed once a month. In the analytical part of the research, the quality of sewage was characterized, the strength of correlation of the examined indicators was determined and the susceptibility of sewage to biological decomposition was assessed. On the basis of the analysis it was found that knowing the value of the COD parameter it is possible to determine the values of the other indicators, i.e. $\mathrm{BOD}_{5}$, TN and TP. Moreover, it was shown that wastewater is largely susceptible to the biological decomposition of pollutants, and during the period when the inflow of sewage with reduced susceptibility occurs, the wastewater with high content of organic carbon should be dosed.
\end{abstract}

Keywords: wastewater, biodegradability, mechanical treatment, Person`s correlation.

\section{INTRODUCTION}

The proper functioning of a wastewater treatment plant starts already at the stage of developing a technological design, because the mistakes made by the designer at this stage will result in malfunctions during the whole period of its operation (Nowobilska-Majewska and Bugajski 2020, Karamus 2018, Moretti 2011). After the construction or modernization of a wastewater treatment plant, its long-term operation is often a complex problem for the operator, because the variability of the quantity and quality of the inflowing wastewater over time may determine the interference of mechanical and biological treatment processes (Trikoilidou et al. 2016, Mailler et al. 2016, Dymaczewski et al. 2011). Therefore, it is important to monitor the quantity and quality of wastewater continuously at each stage of wastewater treatment and to intervene if it is necessary to prevent the possible irregularities in treatment processes (Kaczor 2020, Jóźwiakowska and Marzec 2020, Skoczko et al. 2016). Currently, the design of a technological line of wastewater treatment plant processes is supported by computer programs, which facilitate the designer's work (Klaczyński 2016, Heidrich and Witkowski 2010). However, each computer program requires an initial calibration, i.e. the entry of appropriate and, importantly, current and reliable input data on the quality of wastewater (Xiao et al. 2017, Młynski et al. 2018, Śliz et al. 2019), which is particularly important while designing a biological reactor. The analytical part of this article is a contribution to the knowledge for designers as well as for wastewater treatment plant operators about the size of pollutants in sewage before and after the mechanical treatment process and how to monitor them quickly. 
The aim of the research was to determine the interrelationships between Chemical Oxygen Demand (COD) and Biochemical Oxygen Demand $\left(\mathrm{BOD}_{5}\right)$, Total Nitrogen (TN) and Total Phosphorus (TP) using statistical methods, both in raw sewage and in the wastewater treated mechanically in a collective wastewater treatment plant, which would allow estimating the values of these parameters on the basis of the COD value. Moreover, the aim of the study was to determine the changes in the susceptibility of wastewater before and after mechanical treatment to decomposition of organic and biogenic pollutants. The study was carried out on the basis of the sewage quality data from the treatment plant in Nowy Sącz (Poland).

Research thesis: there is a relationship between the organic and biogenic indicators in the inflowing wastewater and in the wastewater after mechanical treatment, which determines the susceptibility of wastewater to biological decomposition in a biological reactor.

\section{MATERIALS AND METHODS}

\section{Characteristics of the sewerage system}

The sewerage network, which delivers sewage to the analyzed wastewater treatment plant, serves $73 \%$ of the inhabitants living in Nowy Sącz and partially the residents of the neighboring communes, i.e. Stary Sącz, Korzenna, Nawojowa, Kamionka and Grybów. The total number of people using the sewerage system is 140,000 . The discussed network partly consists of the combined sewerage system and partly of the separate sewerage system, while its total length is $579.3 \mathrm{~km}$. In addition, the sewage from non-return tanks called septic tanks is transported to the catchment point of the analyzed wastewater treatment plant by septic trucks.

The examined wastewater treatment plant is located in the northern part of Nowy Sącz (Zabełcze-Wielopole housing estate, ul. Wiklinowa 22) $49^{\circ} 39^{\prime} 31^{\prime \prime} N 20^{\circ} 41^{\prime} 7 "$ E. The facility was designed for an average daily flow of $30,000 \mathrm{~m}^{3} / \mathrm{d}$ and the population equivalent (PE) of 120,000 . The wastewater treatment technology essentially consists of two stages: mechanical and biological. The first mechanical stage of wastewater treatment comprises: automatic grids, grit chambers, grease traps and initial settling tanks. Then, the mechanically treated wastewater goes to a second stage pumping station, where it is pumped into a biological reactor with activated sludge type MUCT. The wastewater from the biological reactor goes to two radial secondary settling tanks and then to a receiver, which is the

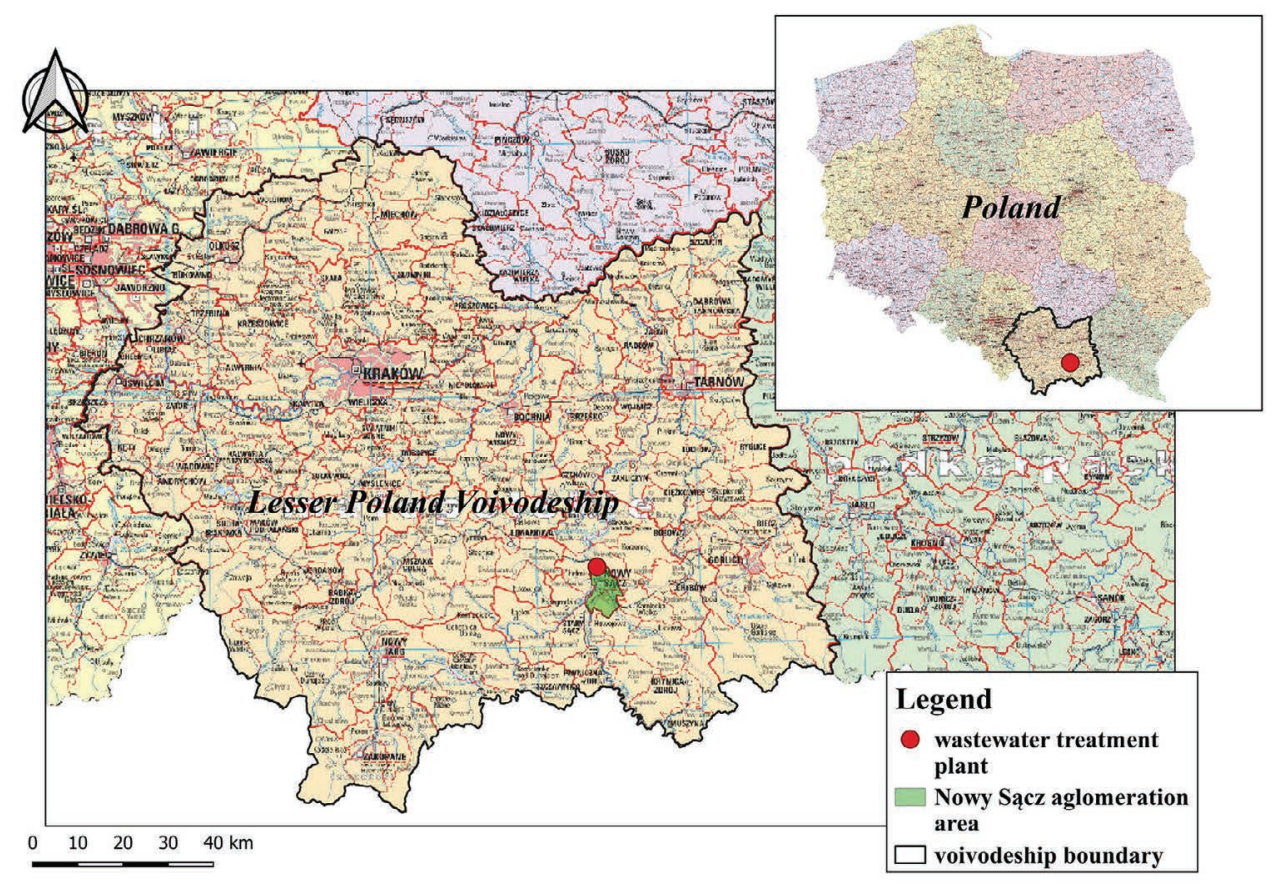

Figure 1. The location of the rural agglomeration of Nowy Sącz against the background of the Masovian Voivodeship and Poland (own study) 
Dunajec River. The figure 1 presents the location of the wastewater treatment plant in Nowy Sącz.

\section{Analytical and Statistical Methods}

The research was conducted during the years 2006-2015. It involved collecting 120 samples of raw and mechanically treated wastewater which were analyzed once a month. The samples of wastewater were subjected to the physical-chemical analysis in accordance to the reference methods set out in the applicable legal acts.

- $\mathrm{BOD}_{5}$ - oxygen measurement after 5 days of incubation at $20^{\circ} \mathrm{C}$ at OXI TOP - 197 WTW

- CODcr - dichromate method according to PN-ISO 6060:2006

- Total Nitrogen-according to PN-EN 25663:200

- Total Phosphorus - Hach DR 2800 spectrophotometer - cuvette tests type LCK 349 and LCK 350

- Statistical analysis regarding Pearson linear correlation, partial correlation and developed nomograms was performed using the "STATISTICA 8" software package (StatSoft, Inc., USA). The significance of the studied connection was checked with the Student's t-test at the significance level $\alpha=0.05$.

\section{RESULTS AND DISCUSSION}

During the 10-year study period, the sewage flowing from the sewerage network to the wastewater treatment plant was characterized by the concentrations typical for domestic sewage, as indicated by Kaczor (2009), Gajewska (2015), Nowobilska-Majewska and Bugajski (2019). In the inflowing sewage the median $\mathrm{BOD}_{5}$ was $346.7 \mathrm{mg} / \mathrm{L}$, while the median COD was $905.0 \mathrm{mg} / \mathrm{L}$. The coefficient of variation $\mathrm{C}_{\mathrm{v}}$ of these organic parameters in the inflowing wastewater was $36 \%$ and $35 \%$ respectively, which indicates their average variation according to the scale given by Mucha (1994). The median concentration of biogenic indicators in the inflowing wastewater was $62.1 \mathrm{mg} / \mathrm{L}$ for TN and $6.6 \mathrm{mg} / \mathrm{L}$ for TP. The coefficient of variation for TN, which was $\mathrm{C}_{\mathrm{v}}=20 \%$, indicates small variation of this parameter in the inflowing wastewater, while for TP $\mathrm{C}_{\mathrm{v}}=28 \%$, which denotes medium variation according to Mucha (1994). Characteristic values of organic and biogenic parameters in sewage flowing into the analyzed wastewater treatment plant are presented in the table 1.

Detailed characteristics concerning the occurrence of concentrations of the analyzed indicators in the inflowing wastewater are presented in the histograms in Figure 2. The histograms illustrate the relative frequency of the concentrations occurrence in particular class ranges along with a matched probability distribution. In the case of $\mathrm{BOD}_{5}$, it was found that the values of this parameter appeared most often in the range from 300 to $400 \mathrm{mg} / \mathrm{L}$ (Fig. 2A). Within this range, 44 events were recorded, which was $36.7 \%$ of the cases. The BOD $_{5}$ values above $600 \mathrm{mg} / \mathrm{L}$ occurred incidentally and accounted for $2.5 \%$ of all the cases. The COD values in the inflowing wastewater oscillated most often between 600 and $1000 \mathrm{mg} / \mathrm{L}$ (Fig. 2B). A total number of 64 events were recorded in these ranges, which accounted for $53.3 \%$ of all the cases. The COD values above $1400 \mathrm{mg} / \mathrm{L}$ occurred occasionally, and constituted $4.2 \%$ of the cases. The TN concentrations in the inflowing wastewater were most often found in the range from 55 to $75 \mathrm{mg} / \mathrm{L}$ (Fig. 2C). A total number of 68 events were recorded in these ranges, which accounted for $56.7 \%$ of the cases. The TP concentrations most often oscillated between 5 and $7 \mathrm{mg} / \mathrm{L}$ (Fig. 2D). A total amount of 53 events were reported in this range, which accounted for $44.2 \%$ of all the events.

In all the cases it was found that the occurrence of the analyzed indicators in the inflowing wastewater had a normal distribution. Therefore, normal distribution can be used as a model

Table 1. Statistical characteristics of concentration indicators in raw wastewater

\begin{tabular}{|c|c|c|c|c|c|c|}
\hline \multirow{3}{*}{ Parameters } & \multicolumn{6}{|c|}{ Statistics } \\
\hline & Average & Median & Max. & Min. & $\begin{array}{l}\text { Standard } \\
\text { deviation }\end{array}$ & $\begin{array}{c}\text { Coefficient of } \\
\text { variation }\end{array}$ \\
\hline & \multicolumn{5}{|c|}{$\mathrm{mg} / \mathrm{L}$} & $\%$ \\
\hline $\mathrm{BOD}_{5}$ & 363.1 & 346.7 & 903.8 & 91.0 & 126.8 & 36 \\
\hline COD & 911.1 & 905.0 & 2211.0 & 262.8 & 326.1 & 35 \\
\hline TN & 60.3 & 62.1 & 86.1 & 25.5 & 12.3 & 20 \\
\hline TP & 6.7 & 6.6 & 10.7 & 2.3 & 1.8 & 28 \\
\hline
\end{tabular}



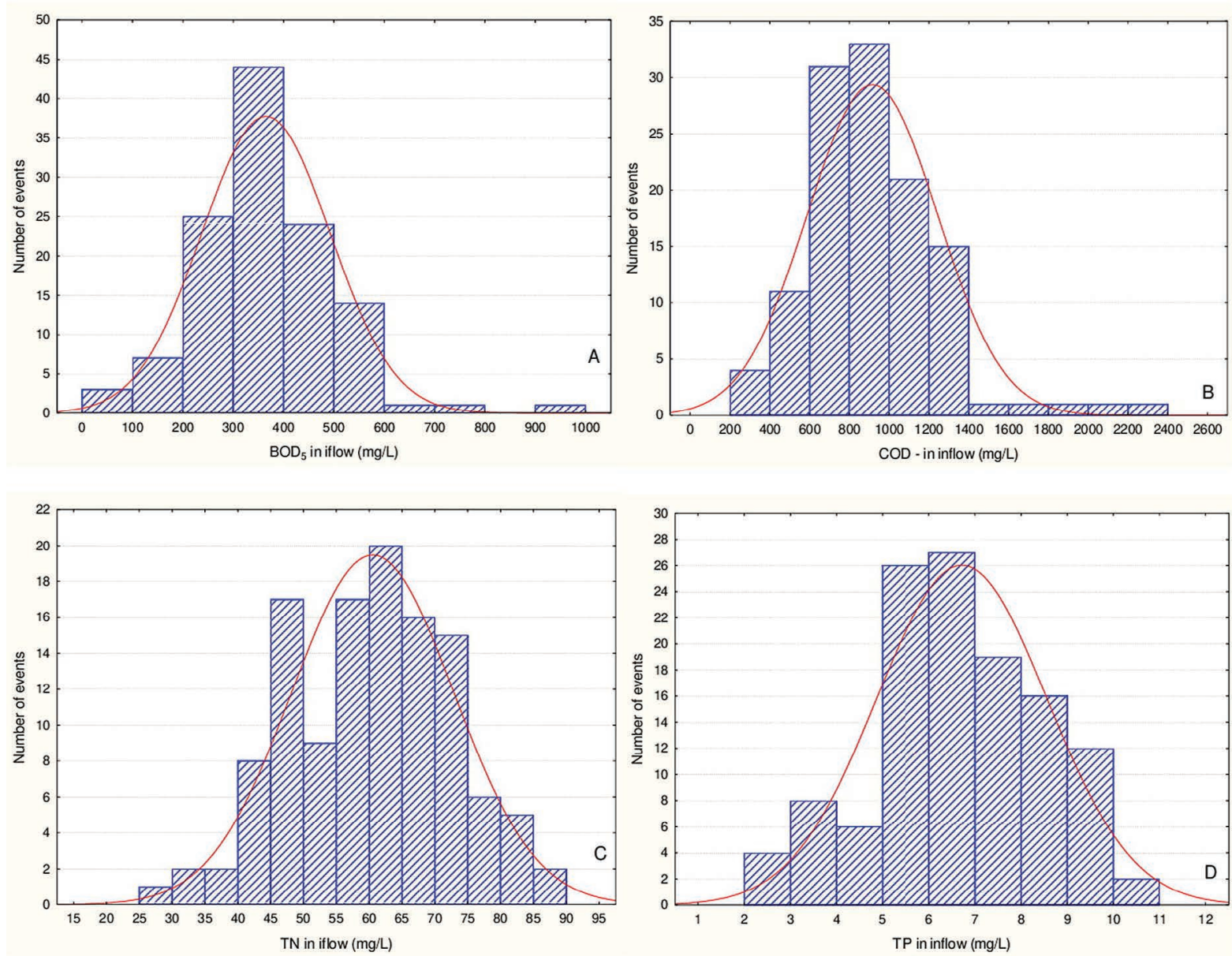

Figure 2. Histogram of occurrence frequency and adjustment of the normal distribution to the empirical distribution of the analyzed indicators $(n=120)$

describing the empirical distribution of the occurrence of the analyzed indicators in the inflowing wastewater (Wasilewska 2011).

Using the data including the COD values (as an independent variable) as a reliable indicator with the possibility of obtaining a quick result and parameter values: $\mathrm{BOD}_{5}$, TN and TP (as dependent variables) the level of linear dependence was developed together with the Pearson correlation coefficient of these variables (Fig. 3A, 3B, 3C.). According to Siwiec et al. (2018) and PhuciennikKoropczuk (2009), on the basis of the COD indicator value, it is possible to accurately estimate the values of other indicators such as $\mathrm{BOD}_{5}$, TN and TP in the analyzed wastewater, which helps to reduce measurement time and costs.

On the basis of the analysis of the interdependence of COD and $\mathrm{BOD}_{5}$ in the inflowing wastewater, it was found that the correlation between these parameters was $\mathrm{r}_{\mathrm{xy}}=0.89$, which in the scale proposed by Guilford (1965) means very high level of correlation. From the equation describing the regression line presented in the figure $3 \mathrm{~A}$, it can be concluded that in the inflowing wastewater, a $1 \mathrm{mg} / \mathrm{L}$ change in the COD value causes a $0.34 \mathrm{mg} / \mathrm{L}$ change in the $\mathrm{BOD}_{5}$ value. The correlation coefficient of the effect of the COD values on the TN concentrations in the inflowing wastewater was $r_{x y}=0.59$, which indicates a high correlation. From the equation describing the regression line shown in the figure $3 \mathrm{~B}$ it can be concluded that a change of the COD value by $1 \mathrm{mg} / \mathrm{L}$ causes a change of the TN concentration by $0.02 \mathrm{mg} / \mathrm{L}$. In the case of the relationship between the COD and TP concentrations in the inflowing wastewater, the correlation was found to be high, which is indicated by the correlation coefficient $r_{x y}=0.67$. In this case, as shown by the regression line equation in the figure $3 \mathrm{C}$, a change in the COD value by $1 \mathrm{mg} / \mathrm{L}$ results in a change in the TP concentration by $0.004 \mathrm{mg} / \mathrm{L}$. In all the analyzed cases, the correlation is statistically significant at a level $\alpha=0.05$.

In the stage of mechanical treatment, the reduction of the analyzed indicators was $35.3 \%$ for $\mathrm{BOD}_{5}, 43.3 \%$ for COD, $5.3 \%$ for $\mathrm{TN}$ and 

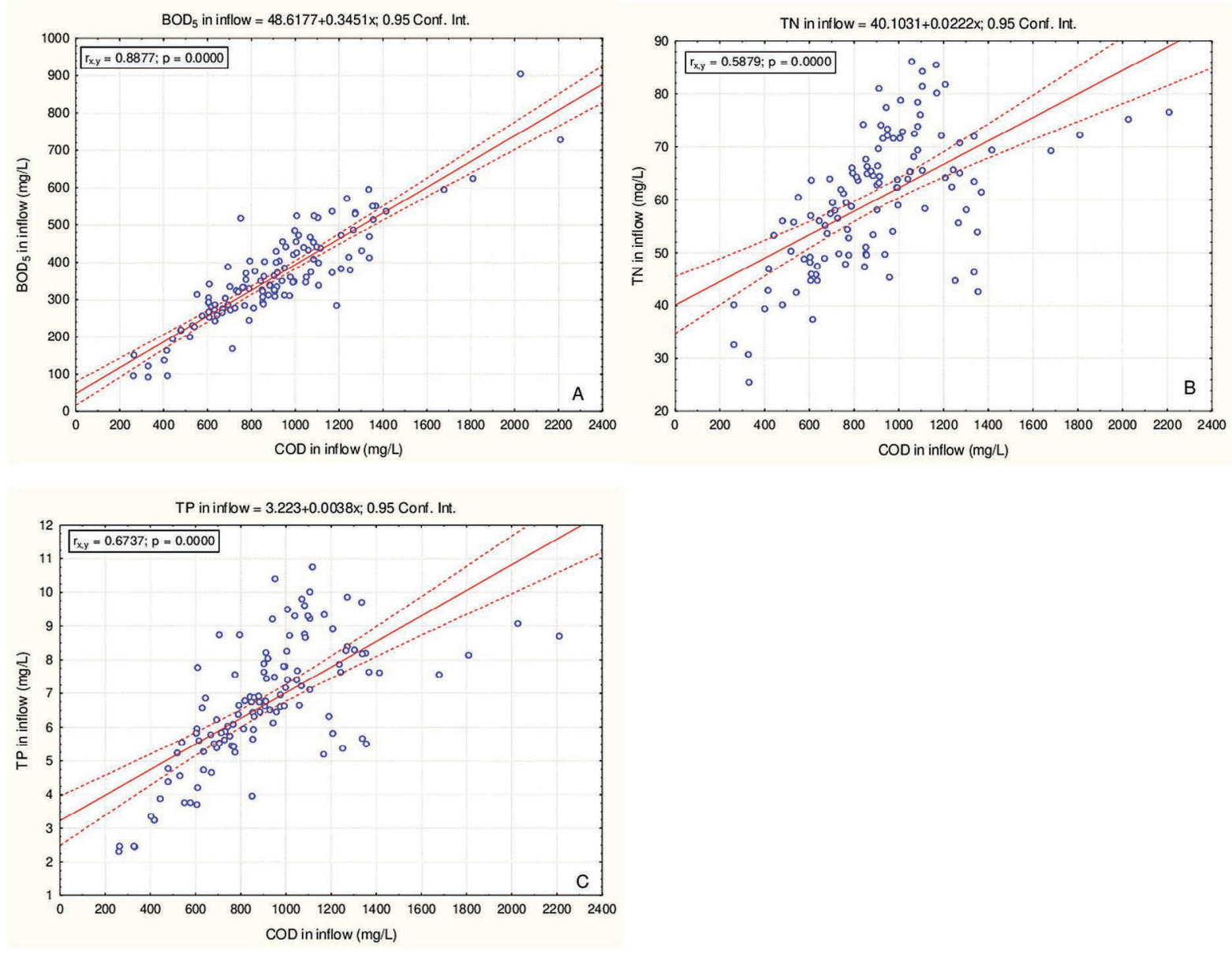

Figure 3. Scatter diagram with a regression line and a 95\% confidence level concerning the effect of COD on $\mathrm{BOD}_{5}(\mathrm{~A}), \mathrm{TN}(\mathrm{B})$ and $\mathrm{TP}(\mathrm{C})$ in the inflowing wastewater

5.1\% for TP. As demonstrated by Chmielowski et al. (2016), Nowobilska-Majewska and Bugajski (2020), this is a typical range of organic and biogenic compounds reduction in the mechanical part of collective wastewater treatment plants. After mechanical treatment the median value of organic indicators was $224.3 \mathrm{mg} / \mathrm{L}$ for $\mathrm{BOD}_{5}$ and $412.9 \mathrm{mg} / \mathrm{L}$ for COD. The median concentration was $59.0 \mathrm{mg} / \mathrm{L}$ for TN and $6.3 \mathrm{mg} / \mathrm{L}$ for TP. Coefficients of variation of the analyzed parameters in the mechanically treated wastewater in each case indicate average variation of the analyzed indicators, according to the scale proposed by Mucha
(1994). The characteristic values of organic and biogenic parameters in the sewage treated mechanically in the wastewater treatment plant in Nowy Sącz are presented in Table 2.

As in the case of the analysis of raw sewage, in order to characterize in detail the concentrations of organic and biogenic indicators in the sewage after mechanical treatment, histograms were prepared (Fig. 4.). They show the relative frequency of occurrence of the concentrations in individual class ranges along with a matched probability distribution.

Table 2. Statistical characteristics of concentration indicators in wastewater after mechanical treatment

\begin{tabular}{|c|c|c|c|c|c|c|}
\hline \multirow{2}{*}{ Parameters } & \multicolumn{7}{|c|}{ Statistics } \\
\cline { 2 - 7 } & Average & Median & Max. & Min. & $\begin{array}{c}\text { Standard } \\
\text { deviation }\end{array}$ & $\begin{array}{c}\text { Coefficient of } \\
\text { variation }\end{array}$ \\
\cline { 2 - 7 } & \multicolumn{7}{|c|}{$\mathrm{mg} / \mathrm{L}$} & \\
\hline $\mathrm{BOD}_{5}$ & 230.6 & 224.3 & 520.2 & 65.0 & 78.6 & 34 \\
\hline COD & 540.3 & 512.9 & 1322.0 & 176.4 & 201.3 & 37 \\
\hline TN & 57.9 & 59.0 & 80.0 & 25.9 & 12.3 & 21 \\
\hline TP & 6.6 & 6.3 & 17.7 & 1.8 & 2.4 & 36 \\
\hline
\end{tabular}



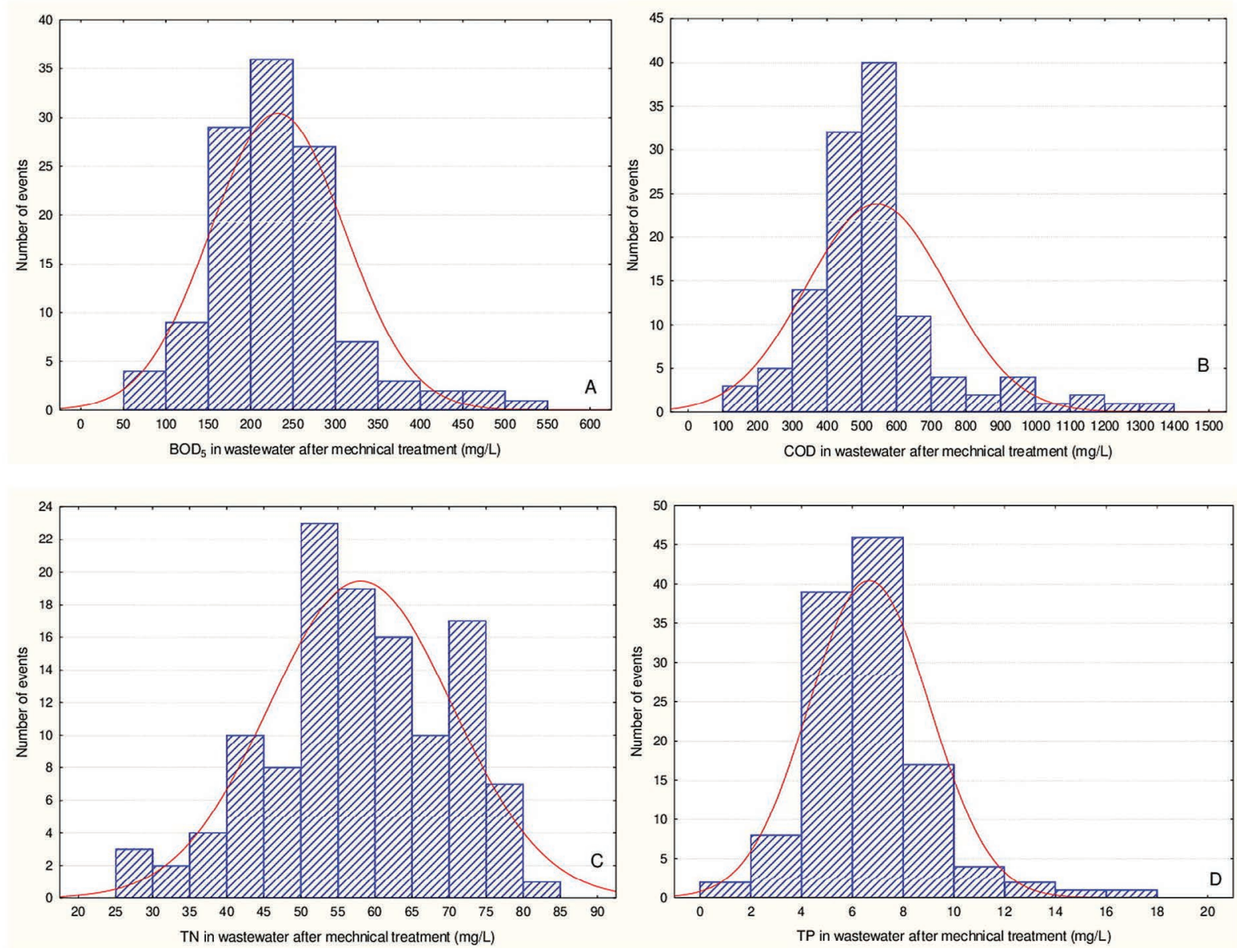

Figure 4. Histogram of occurrence frequency and adjustment of the normal distribution to the empirical distribution of the analyzed indicators $(n=120)$

In the mechanically treated wastewater, the $\mathrm{BOD}_{5}$ values ranged most frequently from 150 to $300 \mathrm{mg} / \mathrm{L}$ (Fig. 4A). In total, 92 events were recorded in these ranges, which is $76.7 \%$. The COD values in mechanically treated wastewater most often oscillated between 400 and $600 \mathrm{mg} / \mathrm{L}$ (Fig. 4B). A total number of 72 events were recorded in these ranges, which accounted for $60.0 \%$ of all the cases. In the case of characteristic TN concentrations in the mechanically treated wastewater, no dominant range was found. It can be stated that the $\mathrm{TN}$ concentrations generally oscillated between 40 and $80 \mathrm{mg} / \mathrm{L}$ (Fig. 4C). In individual class ranges, the TN concentrations occurred with a frequency of $5.8-19.1 \%$ in relation to all the sewage samples. The TP concentrations most often oscillated between 4-6 mg/L and 6-8 mg/L (Fig. 4D). A total amount of 85 cases were reported in this range, representing $70.8 \%$ of all the events.

Similarly as in the case of the inflowing wastewater, in the case of the mechanically treated wastewater, the occurrence of the analyzed indicators had a normal distribution, which indicates that it can serve as a model describing the empirical distribution of the occurrence of the size of the analyzed pollution indicators in the inflowing wastewater (Wasilewska 2011).

Similarly as in the case of the inflowing wastewater, also for the wastewater after mechanical treatment, the level of linear dependence of such parameters as: $\mathrm{BOD}_{5}, \mathrm{TN}$ and $\mathrm{TP}$ as variables dependent on the independent variable COD (Fig. 5A, 5B, 5C.) was developed.

From the point of view of design and subsequent operation of the facility, it is more important to know the quality of wastewater flowing into a biological reactor, i.e. wastewater after mechanical treatment (Barnard 2000, Nowobilska-Majewska and Bugajski 2019, Bugajski and Nowobilska-Majewska 2019). In the mechanically treated wastewater, the dependence of $\mathrm{BOD}_{5}$ on COD expressed by a correlation coefficient was $r_{x y}=0.87$, which indicates a very high level of correlation according to the Guilford scale (1965). From the equation describing 

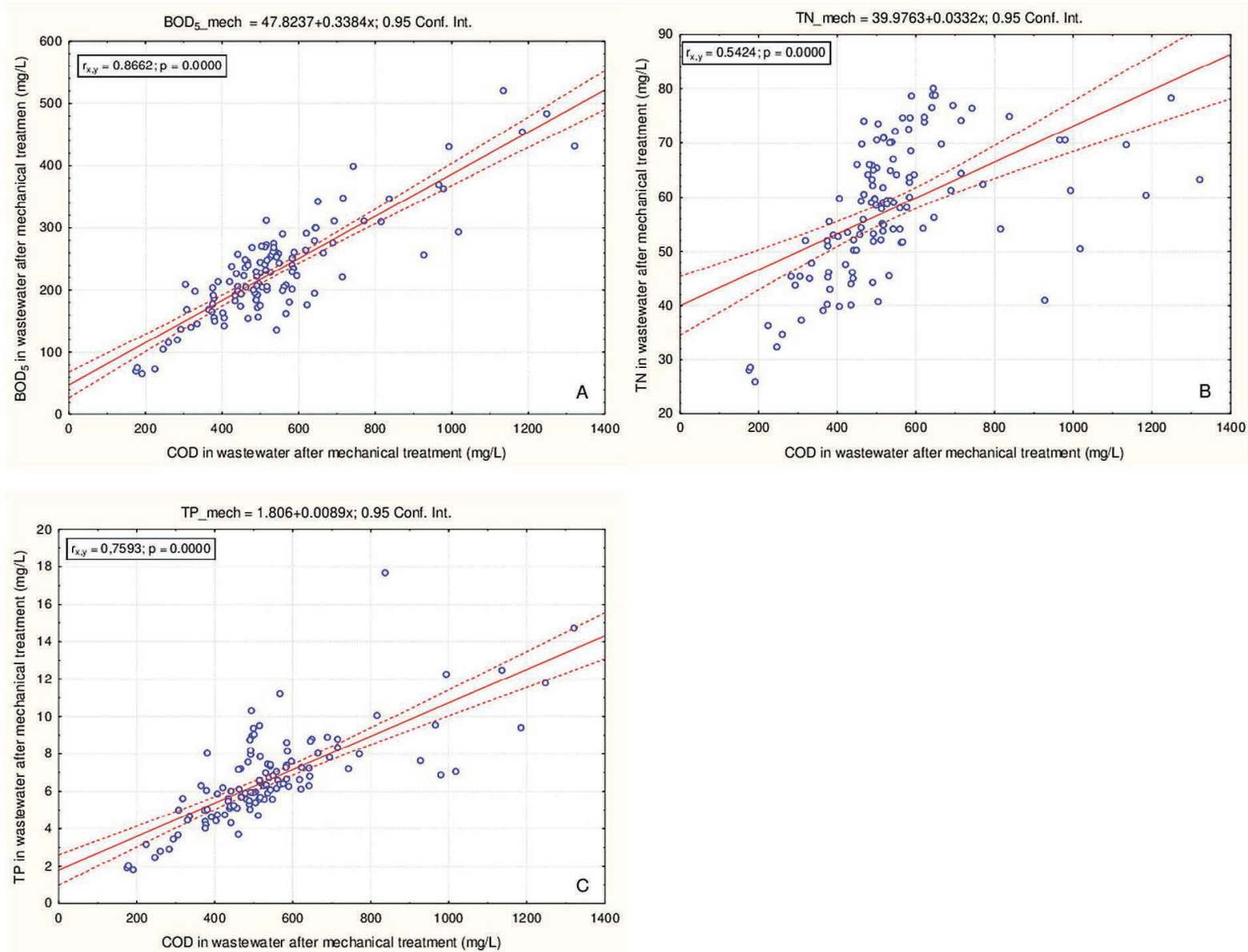

Figure 5. Scatter diagram with a regression line and a $95 \%$ confidence level concerning the effect of COD on $\mathrm{BOD}_{5}(\mathrm{~A}), \mathrm{TN}(\mathrm{B})$ and $\mathrm{TP}(\mathrm{C})$ in the mechanically treated wastewater

the regression line presented in figure $5 \mathrm{~A}$, it can be concluded that in the inflowing wastewater a $1 \mathrm{mg} / \mathrm{L}$ change in the COD value causes a $0.34 \mathrm{mg} / \mathrm{L}$ change in the $\mathrm{BOD}_{5}$ value. The correlation coefficient describing the effect of the COD values on the $\mathrm{TN}$ concentrations in the inflowing wastewater is $r_{x y}=0.54$, which indicates a high correlation. As shown by the equation describing the regression line in the figure $5 \mathrm{~B}$, a change of the COD value by $1 \mathrm{mg} / \mathrm{L}$ causes a change of the TN concentration by $0.03 \mathrm{mg} / \mathrm{L}$. In the case of the dependence of the TP concentrations on the COD values, the correlation was found to be very high, which is indicated by the correlation coefficient $r_{x y}=0.76$. As shown by the equation of the regression line presented in the figure $5 \mathrm{C}$, a $1 \mathrm{mg} / \mathrm{L}$ change of the COD value results in a $0.009 \mathrm{mg} / \mathrm{L}$ change in the TP concentration. In all the analyzed cases, the correlation is statistically significant at a level $\alpha=0.05$.

In the further analytical part of the study, the susceptibility to biological decomposition of the inflowing wastewater and wastewater after mechanical treatment in the analyzed wastewater treatment plant was determined. The assessment of susceptibility to biological decomposition of organic and biogenic pollutants was made on the basis of the dependencies indicated by some researchers (Łomotowski and Szpindor 1999, Miksch and Sikora 2010, Klimiuk and Łebkowska 2003, Młyńska et al. 2017) describing the biodegradability measures:

- $\mathrm{COD} / \mathrm{BOD}_{5} \leq 2.0$ - easy biodegradability

- $\mathrm{COD} / \mathrm{BOD}_{5}>2.0 \leq 2.5-$ average biodegradability

- $\mathrm{COD} / \mathrm{BOD}_{5}>2.5 \leq 5.0$ - poor biodegradability

- $\mathrm{COD} / \mathrm{BOD}_{5}>5.0$ - non-degradable matter

- $\mathrm{BOD}_{5} / \mathrm{TN} \geq 5$ - easy susceptibility of nitrogen compounds to biological degradation

- $\mathrm{BOD}_{5} / \mathrm{TP} \geq 25$ - easy susceptibility of phosphorus compounds to biological degradation

The COD/BOD 5 ratio, which indicated easy susceptibility of wastewater to biological decomposition of organic matter, occurred in $8 \%$ of all the cases (Fig. 6A). In the mechanically treated wastewater, sewage was easily biodegradable in 
$20 \%$ of the cases (Fig. 6B). In both types of sewage, it was found that in about half of the cases ( $47 \%$ and $48 \%$ ) sewage was characterized by average susceptibility to biological decomposition of organic matter. While analyzing the susceptibility of wastewater to the decomposition of biogenic compounds, it was found that in raw sewage the value of the $\mathrm{BOD}_{5} / \mathrm{TN}$ ratio above 5 occurred in $76 \%$ of the cases (Fig. 7A). In the wastewater after mechanical treatment, only in $17 \%$ of the cases the $\mathrm{BOD}_{5} / \mathrm{TN}$ ratio was above 5 , which indicates the susceptibility of sewage. The unfavorable change between the inflowing and mechanically treated wastewater is caused by the fact that the $\mathrm{BOD}_{5}$ reduction rate in the mechanical treatment process is $35.3 \%$, while the TN reduction rate is $5.3 \%$. Therefore, the wastewater after mechanical treatment is too "poor" in organic matter expressed by $\mathrm{BOD}_{5}$. In raw sewage the $\mathrm{BOD}_{5} / \mathrm{TP}$ ratio above 25 occurred in $99 \%$ of the cases (Fig. 8A), while in the mechanically treated sewage it occurred in $90 \%$ of the cases
(Fig. 8B). Similarly as in the previous case, this change results from uneven reduction of organic compounds and phosphorus compounds at the stage of mechanical wastewater treatment.

\section{CONCLUSIONS}

As shown in the analytical part of the study concerning the interdependence of the discussed parameters, it is possible to measure one indicator, i.e. COD, in order to determine the concentration of the remaining indicators, i.e. $\mathrm{BOD}_{5}$, $\mathrm{TN}$ and TP. Thus, the research thesis of this study was proven. In practical terms, the obtained results can help the operators of wastewater treatment plants to control both the quality of raw sewage inflowing from the sewerage system and the quality of the mechanically treated sewage subjected to biological treatment, because the COD measurement gives a picture of the other indicators values. Such type of current quality control of the
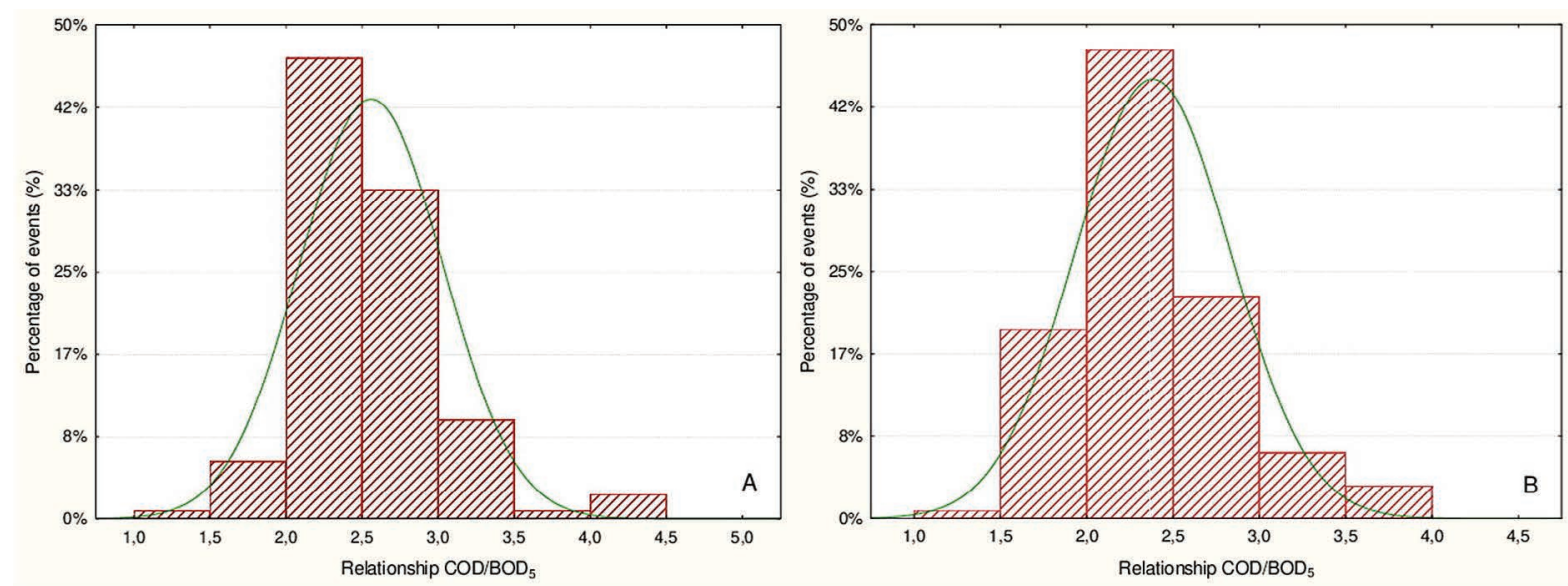

Figure 6. The $\mathrm{COD} / \mathrm{BOD}_{5}$ ratio in the inflowing $(\mathrm{A})$ and mechanically treated $(\mathrm{B})$ wastewater
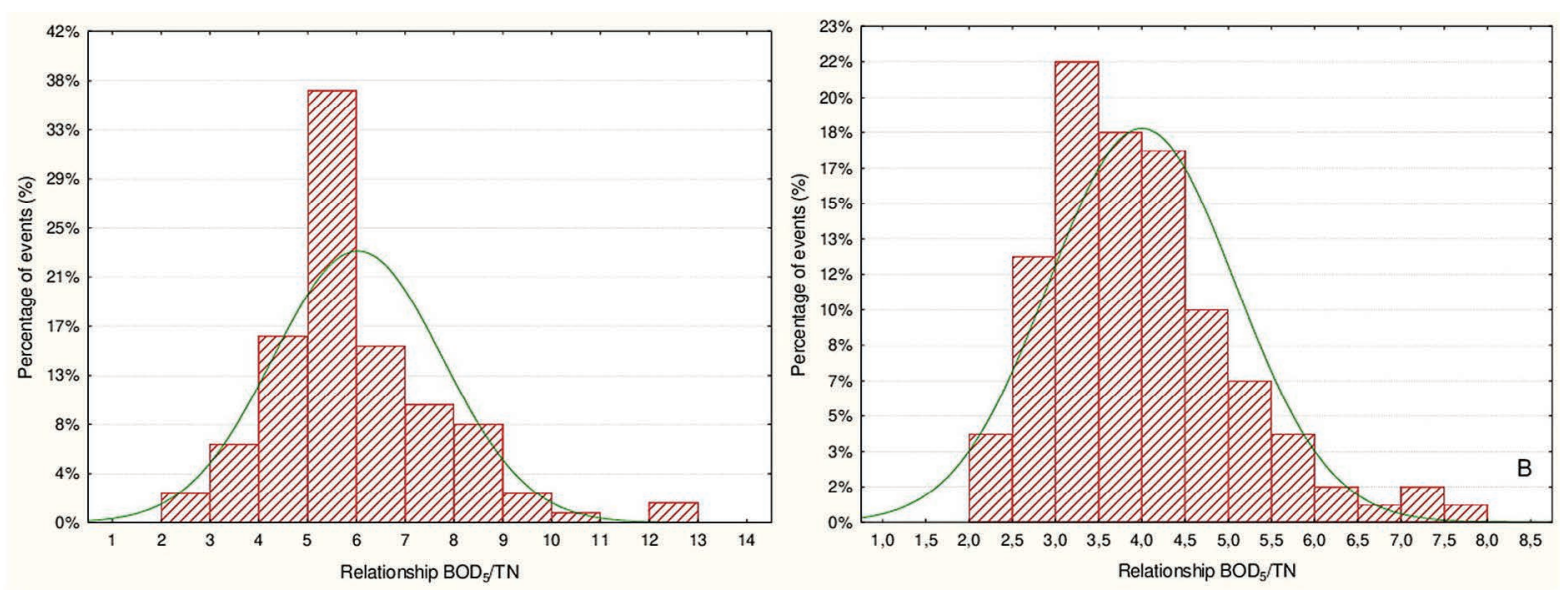

Figure 7. The $\mathrm{BOD}_{5} / \mathrm{TN}$ ratio in the inflowing (A) and mechanically treated (B) wastewater 

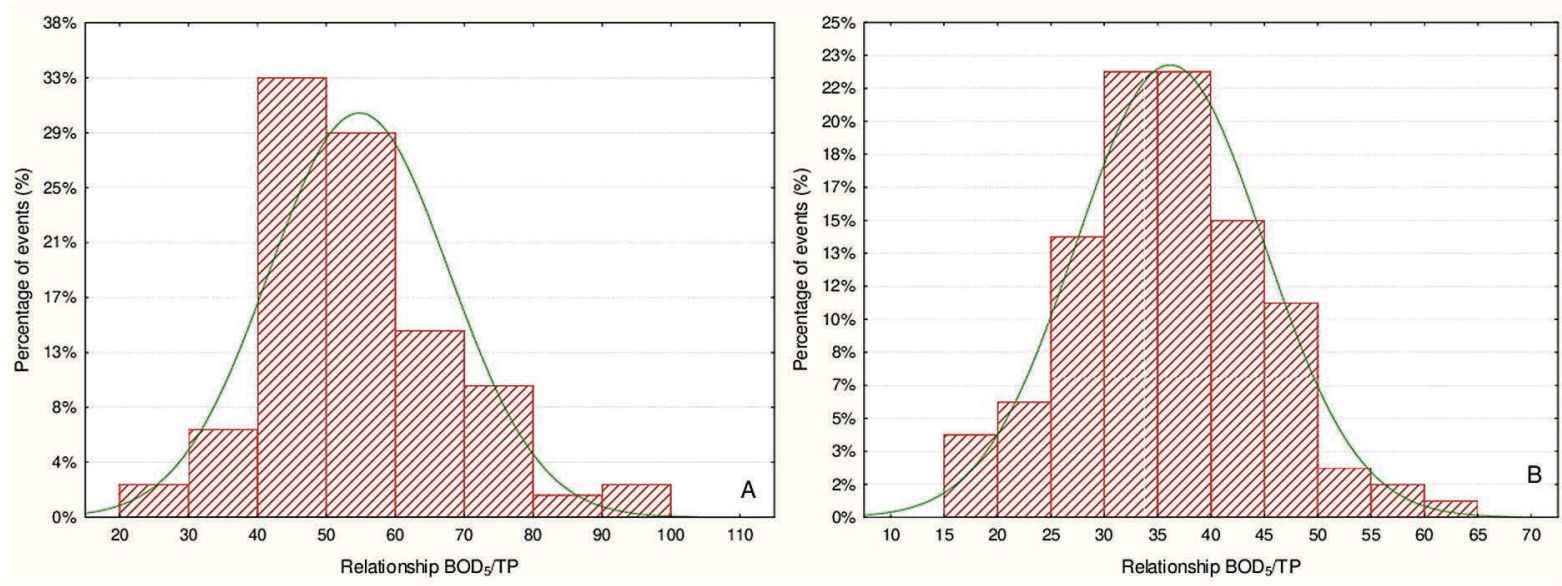

Figure 8. The $\mathrm{BOD}_{5} / \mathrm{TP}$ ratio in the inflowing $(\mathrm{A})$ and mechanically treated (B) wastewater

inflowing as well as mechanically treated wastewater allows optimizing the treatment processes depending on variability. In the analyzed facility, in the period when wastewater after mechanical treatment is poorly susceptible to decomposition of organic and biogenic compounds, it is necessary to deliver (dose) some sewage characterized by high concentration of $\mathrm{BOD}_{5}$ to the wastewater flowing into the bioreactor in the form of easily decomposable organic compounds.

\section{Acknowledgements}

Publication was funded by the Polish National Agency for Academic Exchange under the International Academic Partnerships Programme from the project "Organization of the 9th International Scientific and Technical Conference entitled Environmental Engineering, Photogrammetry, Geoinformatics - Modern Technologies and Development Perspectives".

\section{REFERENCES}

1. Barnard J. L. 2000. The design of wastewater treatment plants with activated sludge removing biogenic compounds. Materials of the training seminar "Design philosophy and operation of wastewater treatment plants". LEM PROJECT s.c. Kraków, 13-60 (in Polish).

2. Bugajski P., Nowobilska-Majewska E. 2019. A Weibull analysis of the reliability of a wastewater treatment plant in Nowy Targ, Poland. Rocznik Ochrony Środowiska, 21, 825-840.

3. Chmielowski K., Bugajski P., Kaczor G. 2016. Compositional analysis of the sewage incoming to and discharged from the sewage treatment plant in
Kolbuszowa Dolna. Journal of Ecological Engineering, 17(5), 9-16.

4. Dymaczewski i in. 2011. The Manual for Operators of Wastewater Treatment Plant. PZITS o/Wielkopolski, Poznań 2011 (in Polish).

5. Gajewska M. 2015. Influence of composition of raw wastewater on removal of nitrogen compounds in multistage treatment wetlands. Environment Protection Engineering, 41, 19-30.

6. Guilford, J. P. 1965. Fundamental statistics in psychology and education. New-York: McGraw-Hill.

7. Heidrich Z., Witkowski A. 2015. Wastewater treatment plants: Design, calculation examples. Wydawnictwo Seidel-Przywecki, Warszawa (in Polish).

8. Jóźwiakowska K., Marzec M. 2020. Efficiency and reliability of sewage purification in long-term exploitation of the municipal wastewater treatment plant with activated sludge and hydroponic system. Archives of Environmental Protection, 46(3), 30-41.

9. Kaczor G. 2009. Concentrations of the pollutants in the sewage drained from the rural sewerage systems in lesser Poland voivodeship. Infrastruktura i Ekologia Terenów Wiejskich, 9, 97-104 (in Polish).

10. Kaczor G. 2020. Changes in concentrations and loads of total phosphorus in domestic and treated wastewater over a 15 -year observation period in terms of limiting negative anthropopressure on the quality of surface water - case study. Acta Sci. Pol., Formatio Circumiectus, 19 (2), 3-14.

11. Karamus Ł. 2018. Wastewater treatment plants and their operation. Wydawnictwo - Kabe, ISBN: 978-83-65382-19-1 (in Polish).

12. Klaczyński E. 2016. Municipal Wastewater Treatment Plants - Fundamentals of Design and Operation. Wyd. Envirotech sp. z o.o. ISBN 978-83-901701-5-2 (in Polish). 
13. Klimiuk E., Łebkowska M. 2003. Biotechnology in environmental protection. Wydawnictwa Naukowe PWN, Warszawa (in Polish).

14. Łomotowski J., Szpindor A. 1999. Modern wastewater treatment systems. Wydawnictwo Arkady, Warszawa (in Polish).

15. Mailler R., Gasperi J., Coquet Y., Buleté A., Vulliet E., Deshayes S., Zedek, S., Mirande-Bret C., Eudes V., Bressy A., Caupos E., Moilleron R., Chebbo G., Rocher V. 2016. Removal of a wide range of emerging pollutants from wastewater treatment plant discharges by micro-grain activated carbon in fluidized bed as tertiary treatment at large pilot scale. Sci. Total Environ., 542, 983-996.

16. Młyńska A., Chmielowski K., Młyński D. 2017. Analysis of wastewater quality changes during treatment processes at the Przemyśl wastewater treatment plant. Ecological Engineering, 18(5), 18-26. (in Polish).

17. Młyński D., Kurek K., Bugajski P. 2018. An Analysis of Seasonal Waste Draining for the Urban Agglomeration Using Statistical Methods. Water, 10, 976.

18. Miksch K., Sikora J. 2010. Wastewater biotechnology. Wydawnictwo Naukowe PWN, Warszawa (in Polish).

19. Moretti C.J., Das D., Kistner B.T., Gullicks H., Hung Y.T. 2011. Activated Sludge and Other Aerobic Suspended Culture Processes. Water, 3, 806-818.

20. Mucha J. 1994. Geostatistical methods in documenting deposits. Script, Department of Mine Geology. AGH Kraków, p. 155. (in Polish)

21. Nowobilska-Majewska E., Bugajski P. 2019. The Analysis of the Amount of Pollutants in Wastewater after Mechanical Treatment in the Aspect of their Susceptibility to Biodegradation in the Treatment Plant in Nowy Targ. Journal of Ecological
Engineering, 20(8), 135-143.

22. Nowobilska-Majewska E., Bugajski P. 2020. The Impact of Selected Parameters on the Condition of Activated Sludge in a Biologic Reactor in the Treatment Plant in Nowy Targ, Poland. Water 2020, 12, 2657.

23. Płuciennik-Koropczuk E. 2009. COD fractions as a measure of wastewater treatment efficiency. Gaz, Woda i Technika Sanitarna, VII-VIII, 11-13 (in Polish).

24. Siwiec T., Reczek L., Michel M., Gut B., HawerStrojek P., Czajkowska J., Jóźwiakowski K., Gajewska M., Bugajski P. 2018. Correlations between organic pollution indicators in municipal wastewater. Archives of Environmental Protection, 44(4), 50-57.

25. Skoczko I., Ofman P., Szatyłowicz P. 2016. Application of artificial neural networks to modeling of wastewater treatment process in a small wastewater treatment plant. Rocznik Ochrony Środowiska, 18, 493-506 (in Polish).

26. Śliz P., Bugajski P., Kurek K. 2019. Effect of selected factors on the removal of organic matter in a model of moving bed biofilm reactor. Archives of Environmental Protection, 45(3), 64-71.

27. Trikoilidou E., Samiotis G., Bellos D,. Amanatidou E. 2016. Sustainable operation of a biological wastewater treatment plant. IOP Conf. Ser.: Mater. Sci. Eng.161 012093.

28. Wasilewska E. 2011. Descriptive statistics from scratch. Wyd. SGGW, Warszawa (in Polish).

29. Xiao H., Huang D., Pan Y., Liu Y., Song K. 2017. Fault diagnosis and prognosis of wastewater processes with incomplete data by the auto-associative neural networks and ARMA model. Chemom. Intell. Lab. Syst., 161, 96-107. 